\title{
Erythropoietin for minimising perioperative allogeneic blood transfusion in open heart surgerv: a systematic review
}

\author{
Panthila Rujirojindakul ${ }^{1}$, Tippawan Liabsuetrakul ${ }^{2}$, Pairaya Rujirojindakul ${ }^{3}$ \\ ${ }^{1}$ Department of Anaesthesiology, ${ }^{2}$ Epidemiology Unit, ${ }^{3}$ Blood Bank and Transfusion Unit, \\ Department of Pathology, Faculty of Medicine, Prince of Songkla University, Songkhla 90110, Thailand
}

\section{Background:}

Erythropoietin increases the ability of bone marrow to produce red blood cells. Elevation of preoperative haemoglobin concentration may be helpful in reducing low perioperative haemoglobin levels, thereby reducing the need for allogeneic red blood cell transfusion.

\section{Objective:}

To assess the efficacy and safety of preoperative erythropoietin in adults who underwent open heart surgery.

\section{Materials and Methods:}

The CENTRAL, MEDLINE, PubMed, EMBASE, ISI Web of Science databases were searched to identify all randomised controlled trials that investigated the effectiveness of preoperative erythropoietin in open heart surgery. The primary outcome was units of allogeneic blood cells transfusion. The secondary outcomes were the number of patients receiving allogeneic blood transfusion, change of haemoglobin levels, and adverse events, especially thromboembolic events and death, and cost of using erythropoietin.

\section{Results and Discussion:}

Data from 11 trials enrolling 840 people are included in this review. We did not perform a meta-analysis for the units of allogeneic blood transfusion and change of haemoglobin levels because statistical heterogeneity was identified in these outcomes. There was no information of complications of allogeneic blood transfusion and cost of using erythropoietin.

\section{Conclusions:}

Preoperative erythropoietin administration reduces the number of patients receiving perioperative allogeneic blood transfusion in adult undergoing open heart surgery. There is no evidence that erythropoietin improves outcomes for volume of allogeneic blood transfusion, change of haemoglobin, mortality, and thromboembolic events.

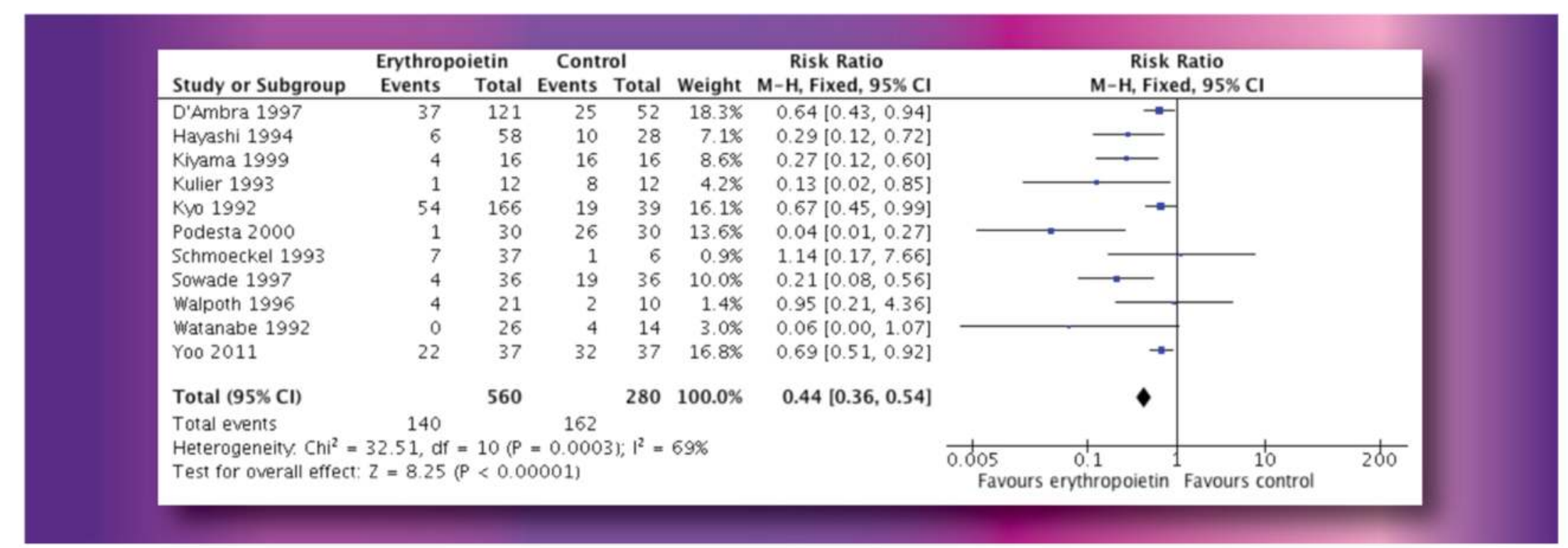

Figure 1. Number of patients receiving allogeneic red blood cells transfusion between erythropoietin and control

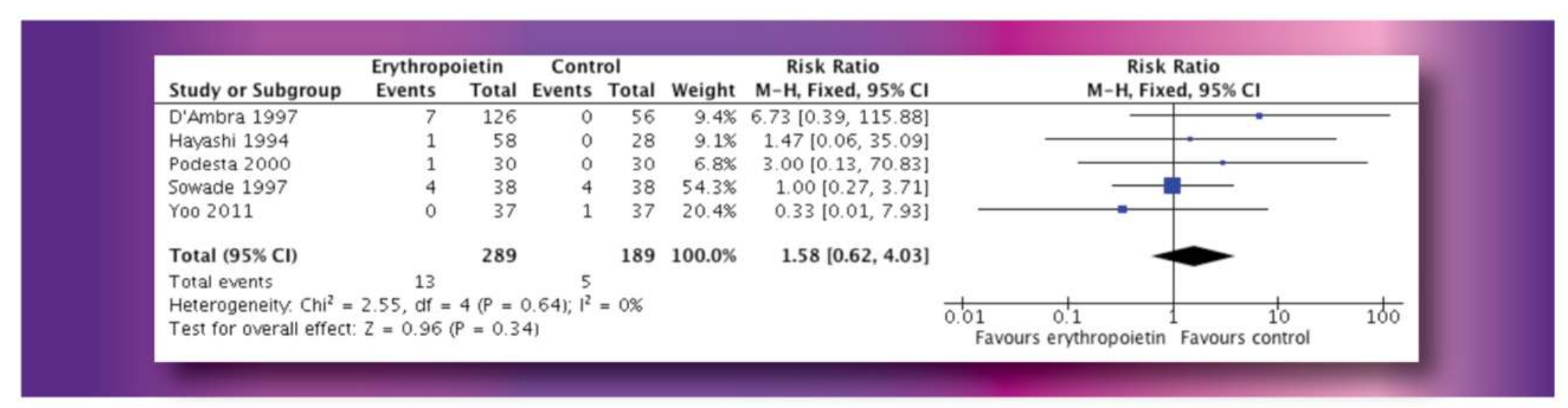

Figure 2. Mortality between erythropoietin and control

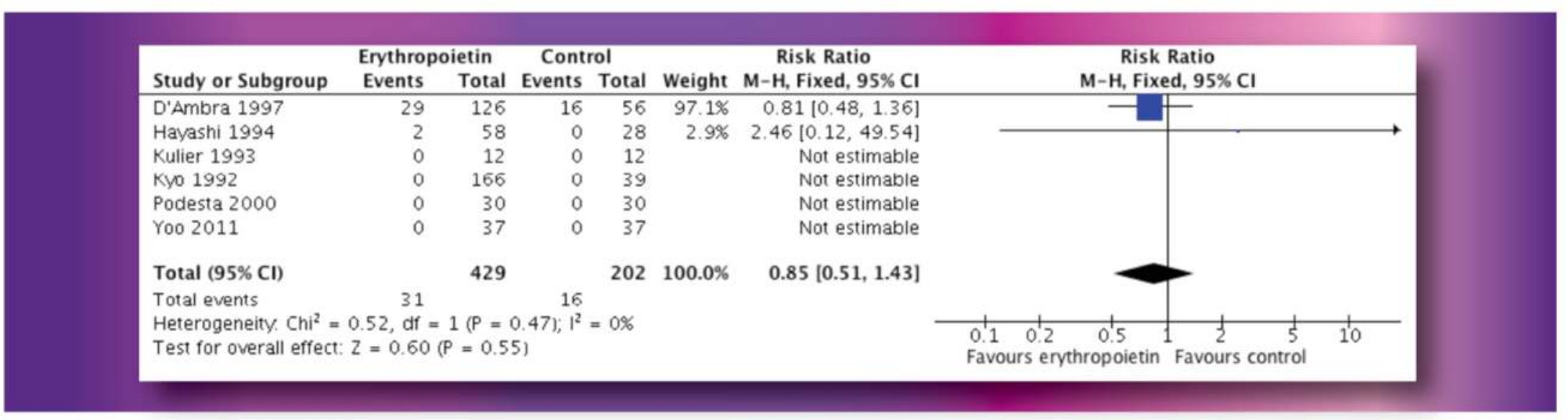

Figure 3. Thromboembolic events between erythropoietin and control 